\title{
Peran dan Strategi Pengembangan Subsektor Peternakan Untuk Menunjang Perekonomian Kota Yogyakarta
}

\section{Role and Stategy of Livestock Subsector Development to Support Economy of Yogyakarta City}

\author{
Anggraeini Puspitasari*, Budi Widayanto, Dwi Aulia Puspitaningrum \\ Program Studi Agribisnis Jurusan Agribisnis Fakultas Pertanian Universitas \\ Pembangunan Nasional Veteran Yogyakarta \\ Jl. SWK 104 (Lingkar Utara) Condongcatur Yogyakarta Indonesia 55283 \\ *Email korespondensi : anggraeinipus@gmail.com
}

Diterima tanggal : 7 Desember 2021 ; Disetujui tanggal : 30 Desember 2021

\begin{abstract}
Yogyakarta was one of the major cities as well as the provincial capital of the Special Region of Yogyakarta. Despite being an urban center, the agricultural sector was able to contribute to the economy of the city, especially the livestock subsector. The aims of this research to (1) analyze the role of the livestock subsector in Yogyakarta City and (2) analyze the development strategy of the livestock subsector to support the local economy of Yogyakarta City. The research method used a descriptive method. This type of research was a case study. The method of retrieval of respondents used a purposive sampling method. The data sources used are primary data and secondary data. Data collection techniques used Focus Group Discussion (FGD), observation, interviews, literature studies, and documentation. Technical data analysis uses Location Quotient (LQ), matrix analysis techniques Internal Faktor Evaluation (IFE), matrix External Faktor Evaluation (EFE), Internal-External matrix (IE), matrix Strength, Weakness, Opportunities, and Threats (SWOT), and Quantitive Strategic Planning Matrix (QSPM). The results of research were (1) livestock subsector became a subsector of base in Yogyakarta so that has role to be main driving subsector to economy of Yogyakarta City (2) the strategy of developing livestock subsector that can be applied in Yogyakarta City was product development strategy to improve quality of livestock products and maximize processing of livestock waste products.
\end{abstract}

Keywords: development strategy, livestock subsector, local economy, location quotient

\begin{abstract}
ABSTRAK
Kota Yogyakarta merupakan salah satu kota besar sekaligus menjadi ibukota provinsi dari Daerah Istimewa Yogyakarta. Meskipun menjadi pusat perkotaan, sektor pertanian masih mampu memberikan kontribusi terhadap perekonomian di kota ini, khususnya di bidang peternakan. Penelitian ini bertujuan (1) menganalisis peran subsektor peternakan di Kota Yogyakarta, (2) menganalisis strategi pengembangan subsektor peternakan untuk mendukung ekonomi lokal Kota
\end{abstract}


Yogyakarta. Metode penelitian yang digunakan yaitu menggunakan metode deskriptif. Jenis penelitian yaitu studi kasus. Metode pengambilan responden menggunakan metode purposive sampling. Teknik pengumpulan data menggunakan Focus Group Discussion (FGD), observasi, wawancara, studi literatur, dan dokumentasi. Teknis analisis data menggunakan analisis Location Quotient (LQ, matriks Internal Faktor Evaluation (IFE), matriks External Faktor Evaluation (EFE), matriks Internal-Eksternal (IE), matriks Strength, Weakness, Opportunities, dan Threats (SWOT), dan Quantitive Strategic Planning Matrix (QSPM). Hasil penelitian menunjukkan bahwa (1) Subsektor peternakan menjadi subsektor basis di Kota Yogyakarta sehingga subsektor peternakan memiliki peran menjadi subsektor penggerak utama terhadap perekonomian Kota Yogyakarta, (2) Strategi pengembangan subsektor peternakan yang dapat diterapkan di Kota Yogyakarta adalah strategi pengembangan produk cara perbaikan kualitas ternak untuk menghasilkan produk ternak yang aman dan memaksimalkan pengolahan produk limbah ternak.

Kata Kunci: Strategi pengembangan, subsektor peternakan, ekonomi lokal, location quotient

\section{PENDAHULUAN}

Kota Yogyakarta merupakan ibukota provinsi dari Daerah Istimewa Yogyakarta, dalam menjalankan kegiatan otonominya pemerintah memanfaatkan potensi sumber daya yang dimiliki. Pengelolaan potensi diharapkan mampu meningkatkan Produk Domestik Regional Bruto (PDRB) daerah. PDRB daerah digunakan sebagai indikator kesejahteraan suatu daerah. Sektor Pertanian di Kota Yogyakarta masih mampu memberikan kontribusi terhadap perekonomian daerah. Lapangan usaha sektor pertanian terdiri dari beberapa subsektor antara lain subsektor tanaman pangan, subsektor tanaman hortikultura, subsektor tanaman perkebunan, subsektor peternakan, serta subsektor jasa pertanian dan perburuan.

Subsektor peternakan merupakan subsektor yang unggul dibandingkan dengan subsektor lainnya. Hal ini dapat diketahui melalui jumlah sumbangan PDRB dari subsektor peternakan yang jumlahnya lebih tinggi dari subsektor pertanian lainnya. Subsektor peternakan meliputi usaha dibidang peternakan yang menyelenggarakan pembibitan serta budidaya segala jenis ternak dan unggas dengan tujuan untuk dikembangbiakan, dibesarkan, dipotong, dan diambil hasilnya, baik yang dilakukan rakyat maupun oleh perusahaan peternakan. Selain itu, subkategori ini juga mencakup pembudidayaan ternak maupun unggas yang 
Puspitasari et.al., Peran dan Strategi Pengembangan Subsektor Peternakan Untuk..

menghasilkan produk berulang, contohnya yaitu susu dan telur. Komoditas yang dihasilkan oleh kegiatan peternakan antara lain sapi potong, kerbau, kambing, domba, babi, kuda, ayam bukan ras (buras), ayam ras pedaging, ayam ras petelur, itik manila, itik, telur ayam ras, telur ayam bukan ras, telur itik, susu segar, dan lainlain (BPS, 2020).

Kegiatan disubsektor peternakan selain melibatkan para pelaku usaha tentunya juga melibatkan beberapa komponen lain baik dari institusi pemerintah maupun masyarakat. Laju pertumbuhan PDRB subsektor peternakan yang setiap tahunnya juga masih belum stabil, bahkan rata-ratanya pun berada diurutan terakhir diantara subsektor yang memiliki rata-rata laju pertumbuhan yang positif. Padahal, subsektor peternakan menjadi subsektor yang memiliki banyak pengaruh dalam kehidupan sehari-hari, sebagai contoh bidang peternakan dapat menjadi penyedia protein hewani, penyedia bahan baku industri, bahkan menjadi salah satu bidang yang dapat melakukan penyerapan tenaga kerja.

Tidak stabilnya kondisi subsektor tersebut maka perlu adanya peran dari pemerintah maupun lembaga serta organisasi masyarakat terkait untuk mendukung pengembangan subsektor tersebut. Pemerintah Kota Yogyakarta melalui Dinas Pertanian dan Pangan Kota Yogyakarta memiliki kebijakan salah satunya untuk meningkatkan pembinaan budidaya peternakan dan perikanan. Peran dari subsektor peternakan itu sendiri perlu diketahui sehingga nantinya dapat dijadikan pertimbangan dan juga dapat dirumuskan serta direkomendasikan suatu strategi. Tujuan dari penelitian ini yaitu untuk menganalisis peran subsektor peternakan terhadap perekonomian Kota Yogyakarta dan menganalisis strategi pengembangan subsektor peternakan untuk mendukung ekonomi lokal Kota Yogyakarta.

\section{METODE PENELITIAN}

Metode penelitian yang digunakan yaitu metode deskriptif kuantitatif, metode deskriptif. Metode ini digunakan untuk membuat deskripsi, gambaran yang sistematis dan akurat mengenai fakta, sifat, dan hubungan dari antar fenomena yang diteliti (Nazir, 2014). Metode kuantitatif sebagai metode ilmiah karena telah memenuhi kaidah ilmiah yang konkrit, objektif, terukur, rasional, dan sistematis. 
(Sugiyono, 2019). Penelitian yang digunakan merupakan jenis penelitian studi kasus karena penelitian ini menggunakan subjek penelitian yang berkaitan dengan hal yang spesifik atau khas dari keseluruhan personalitas (Maxfield dalam Nazir, 2014). Ciri khas yang dimiliki subjek penelitian yaitu Kota Yogyakarta merupakan pusat perkotaan namun sektor pertanian di kota tersebut masih berkontribusi terutama subsektor peternakannya. Subsektor peternakan menjadi penyumbang PDRB sektor pertanian paling tinggi diantara subsektor-subsektor lainnya.

Pemilihan responden untuk penelitian didasarkan pada responden yang memahami kondisi subsektor peternakan di Kota Yogyakarta. Responden penelitian ini mencakup Kepala Bidang Pertanian Dinas Pertanian dan Pangan, Kepala Seksi Bimbingan Usaha Pertanian Dinas Pertanian dan Pangan, Kepala Seksi Sarana dan Prasarana Dinas Pertanian dan Pangan Kota Yogyakarta, Koordinator Penyuluh Pertanian, dan Penyuluh Pertanian. Jenis data yang digunakan pada penelitian ini mencakup data primer dan data sekunder. Pengumpulan data yang digunakan untuk penelitian ini mencakup Focus Group Discussion (FGD), wawancara, observasi, studi literatur, dokumentasi, dan kuisioner. Pengujian instrument penelitian menggunakan uji validitas dan uji reliabilitas, kedua uji tersebut digunakan untuk kuisioner Internal Factor Evaluation (IFE) dan External Factor Evaluation (EFE).

Analisis yang digunakan untuk mengetahui peran subsektor peternakan dapat menggunakan Location Quotient (LQ), LQ merupakan perbandingan relative antara kemampuan sektor yang sama pada wilayah yang lebih luas. Berbagai dasar ukuran dalam penggunaan metode LQ harus disesuaikan dengan kepentingan penelitian dan sumber data yang tersedia (Rustiadi, 2011). Kemudian analisis yang digunakan untuk menganalisis strategi pengembangan subsektor peternakan untuk mendukung ekonomi lokal Kota Yogyakarta yaitu matriks Internal Faktor Evaluation (IFE), matriks External Faktor Evaluation (EFE), matriks InternalEksternal (IE), matriks Strength, Weakness, Opportunities, dan Threats (SWOT), dan Quantitive Strategic Planning Matrix (QSPM). Matriks Internal External (Matriks IE) digunakan untuk mencocokan hasil total skor matriks IFE dan matriks EFE dengan cara menentukan titik perpotongan dari nilai total skor masing-masing 
Puspitasari et.al., Peran dan Strategi Pengembangan Subsektor Peternakan Untuk..

matriks (David, 2016). Analisis SWOT (Strength, Weakness, Opportunities, Threats) merupakan tahap pencocokan yang dapat digunakan untuk membantu mengembangkan empat jenis strategi. Strategi-strategi tersebut antara lain 1) Strategi SO (Strength-Opportunity), 2) Strategi WO (Weakness-Opportunity), 3) Strategi ST (Strength-Threat) dan 4) Strategi WT (Weakness-Threat) (Setyowati, 2017). SWOT juga akan menghasilkan empat kuadran, kuadran 1 merupakan strategi mendukung agresif, kuadran 2 merupakan strategi mendukung diversifikasi, kuadran 3 merupakan strategi mendukung turn-around, dan kuadran 4 merupakan strategi mendukung difensif (Rangkuti, 2018). Analisis QSPM (Quantitative Strategic Planning Matrix) digunakan untuk menentukan daya tarik dari setiap strategi alternatif yang dibangun berdasarkan faktor internal dan eksternal yang ada. Penentuan bobot, rating, dan Attractive Score untuk setiap kriteria didapatkan melalui meminta pendapat responden yang dianggap ahli dan mengetahui tentang objek penelitian (Yulia, 2015).

\section{HASIL ANALISIS DAN PEMBAHASAN}

\section{Peran Subsektor Peternakan di Kota Yogyakarta}

Peran tersebut dapat diketahui melalui analisis Location Quotient (LQ) pada rentan waktu tahun 2010-2019. Dasar perhitungan LQ dapat mengguanakan jumlah produksi, jumlah tenaga kerja, maupun pendapatan. Perhitungan LQ dapat menggunakan variabel tenaga kerja atau menggunakan PDRB suatu wilayah sebagai indikator pertumbuhan wilayah (Puradireja, 2021). Perhitungan LQ menggunakan perbandingan PDRB Atas Dasar Harga Konstan dengan tahun dasar 2010, hal ini dipilih karena untuk mengetahui potensi aktivitas ekonomi maka pendapatan dapat dijadikan dasar ukuran yang dipilih.

Menurut perhitungan menggunakan analisis Location Quotient (LQ), dapat diketahui bahwa subsektor peternakan memiliki nilai rata-rata LQ sebesar 3,317, angka tersebut lebih dari 1 sehingga subsektor tersebut menjadi subsektor basis yang memiliki peranan sangat penting terhadap perekonomian Kota Yogyakarta. Peran subsektor peternakan terhadap kondisi perekonomian Kota Yogyakarta antara lain budidaya peternakan sebagai usaha untuk meningkatkan pendapatan 
Jurnal Dinamika Sosial Ekonomi, 22 (2) : 179-193

masyarakat, menciptakan lapangan usaha, penyedia bahan baku industri pengolahan, dan sebagai pemenuhan kebutuhan masyarakat terhadap produk hewani.

Tabel 1. Nilai Location Quotient (LQ) Sektor Pertanian Kota Yogyakarta Tahun 2010-2019

\begin{tabular}{crrrrr}
\hline \multirow{2}{*}{ Tahun } & \multicolumn{5}{c}{ Subsektor } \\
\cline { 2 - 6 } & Peternakan & $\begin{array}{c}\text { Tanaman } \\
\text { Pangan }\end{array}$ & $\begin{array}{c}\text { Tanaman } \\
\text { Hortikultura }\end{array}$ & $\begin{array}{c}\text { Tanaman } \\
\text { Perkebunan }\end{array}$ & $\begin{array}{c}\text { Jasa Pertanian } \\
\text { dan Perburuan }\end{array}$ \\
\hline 2010 & 3,556 & 0,210 & 0,469 & 0,004 & 1,000 \\
2011 & 3,396 & 0,221 & 0,502 & 0,004 & 1,009 \\
2012 & 3,535 & 0,228 & 0,477 & 0,004 & 1,073 \\
2013 & 3,586 & 0,234 & 0,516 & 0,004 & 1,150 \\
2014 & 3,306 & 0,240 & 0,681 & 0,004 & 1,046 \\
2015 & 3,228 & 0,210 & 0,484 & 0,004 & 0,926 \\
2016 & 3,215 & 0,207 & 0,489 & 0,004 & 0,921 \\
2017 & 3,159 & 0,207 & 0,479 & 0,004 & 0,905 \\
2018 & 3,105 & 0,210 & 0,482 & 0,004 & 0,908 \\
2019 & 3,086 & 0,208 & 0,485 & 0,004 & 0,922 \\
\hline Rata-rata & 3,317 & 0,218 & 0,506 & 0,004 & 0,985 \\
\hline Sumberyyyyy
\end{tabular}

Sumber : BPS Kota Yogyakarta dan Provinsi Daerah Istimewa Yogyakarta (2015 dan 2020) (data diolah)

Subsektor lainnya yaitu subsektor tanaman pangan, subsektor tanaman hortikultura, subsektor tanaman perkebunan dan subsektor jasa pertanian memiliki nilai Location Quotient (LQ) < 1 sehingga subsektor-subsektor tersebut merupakan subsektor non-basis sehingga peran subsektor tersebut terhadap perekonomian di Kota Yogyakarta lebih rendah. Sektor jasa pertanian dan perburuan di lima tahun pertama mulai tahun 2010 hingga 2014 juga memiliki nilai LQ > 1 namun di tahun 2015 hingga tahun 2019, ini kondisi menunjukkan peran subsektor jasa pertanian dan perburuan terhadap perkonomian Kota Yogyakarta menjadi lebih rendah.

\section{Strategi Pengembangan Subsektor Peternakan Untuk Mendukung Ekonomi}

\section{Lokal Kota Yogyakarta}

Analisis Internal Factor Evaluation (IFE) \& External Factor Evaluation (EFE)

Matriks ini digunakan untuk mengetahui pengaruh faktor internal terhadap kondisi subsektor peternakan Kota Yogyakarta. Faktor yang menjadi kekuatan dan 
Puspitasari et.al., Peran dan Strategi Pengembangan Subsektor Peternakan Untuk..

kelemahan utama subsektor peternakan Kota Yogyakarta dapat diketahui melalui matriks IFE.

Tabel 2. Hasil Matriks IFE (Internal Factor Evaluation)

\begin{tabular}{lcrr}
\hline \multicolumn{1}{c}{ Faktor Internal } & $\begin{array}{c}\text { Bobot } \\
\text { (a) }\end{array}$ & $\begin{array}{c}\text { Rating } \\
\text { (b) }\end{array}$ & $\begin{array}{c}\text { Skor } \\
\text { (a x b) }\end{array}$ \\
\hline Kekuatan & & & \\
\hline Ketersediaan sumber daya alam & 0,10 & 3,33 & 0,33 \\
Basis ekonomi peternakan & 0,10 & 3,33 & 0,33 \\
Koordinasi antar seksi/bidang/lembaga & 0,11 & 3,33 & 0,38 \\
Kebijakan dari pemerintah & 0,10 & 3,17 & 0,32 \\
Terdapat kelompok ternak & 0,11 & 3,17 & 0,35 \\
Pengelolaan sarana yang ada & 0,11 & 3,17 & 0,36 \\
\hline Jumlah & 0,64 & 19,50 & 2,07 \\
\hline Kelemahan & & & \\
\hline Kurang meratanya persebaran komoditas peternakan & 0,05 & 1,50 & 0,07 \\
Pengetahuan yang dimiliki peternak rendah & 0,06 & 1,83 & 0,11 \\
Peternak belum satu visi dalam mengembangkan & 0,06 & 1,50 & 0,09 \\
peternakan & & & \\
Minimnya kegiatan dari pemerintah di bidang & 0,05 & 1,50 & 0,08 \\
peternakan & & & \\
Keterbatasan modal usaha & 0,07 & 1,67 & 0,12 \\
Belum semua peternak melakukan pengolahan & 0,07 & 1,67 & 0,12 \\
produk & & & \\
\hline Jumlah & 0,36 & 9,67 & 0,59 \\
\hline Total Skor Tertimbang & 1,00 & 29,17 & 2,66 \\
\hline Sumber : Data pring
\end{tabular}

Sumber : Data primer diolah (2021)

Faktor yang menjadi kekuatan utama subsektor peternakan Kota Yogyakarta adalah koordinasi antar seksi/bidang/lembaga dengan skor sebesar 0,38. Sedangkan faktor yang menjadi kelemahan utama subsektor peternakan Kota Yogyakarta adalah kurang meratanya persebaran komoditas peternakan. Total skor tertimbang yang didapatkan dari analisis menggunakan Matriks IFE menunjukan nilai sebesar 2,66, nilai tersebut menunjukkan posisi internal yang kuat.

Matriks EFE (External Factor Evaluation) menggambarkan kondisi lingkungan eksternal subsektor peternakan Kota Yogyakarta. Matriks ini digunakan untuk mengetahui pengaruh faktor eksternal terhadap kondisi subsektor peternakan Kota Yogyakarta. Faktor yang menjadi kekuatan dan kelemahan utama subsektor peternakan Kota Yogyakarta dapat diketahui melalui Matriks EFE. 
Jurnal Dinamika Sosial Ekonomi, 22 (2) : 179-193

Tabel 3. Hasil Matriks EFE (External Factor Evaluation)

\begin{tabular}{lcrr}
\hline \multicolumn{1}{c}{ Faktor Eksternal } & $\begin{array}{c}\text { Bobot } \\
\text { (a) }\end{array}$ & \multicolumn{1}{c}{$\begin{array}{c}\text { Rating } \\
\text { (b) }\end{array}$} & $\begin{array}{c}\text { Skor } \\
\text { (axb) }\end{array}$ \\
\hline Peluang & & & \\
\hline $\begin{array}{l}\text { Kota Yogyakarta sebagai jalur distribusi pangan } \\
\text { Ketertarikan masyarakat terhadap peternakan }\end{array}$ & 0,10 & 3,83 & 0,39 \\
bersifat rekreasi dan hobi & 0,09 & 3,50 & 0,30 \\
Pertumbuhan ekonomi & & & \\
Kebutuhan pangan hewani meningkat & 0,10 & 3,50 & 0,34 \\
Pengolahan limbah ternak & 0,09 & 3,50 & 0,32 \\
Meningkatnya permintaan komoditas ternak di kondisi & 0,09 & 3,33 & 0,31 \\
tertentu & 0,10 & 3,33 & 0,32 \\
\hline Jumlah & 0,57 & 21,00 & 1,98 \\
\hline Ancaman & & & \\
\hline Adanya penyakit ternak & 0,06 & 2,33 & 0,14 \\
Adanya kasus pencurian ternak & 0,09 & 2,33 & 0,20 \\
Protes masyarakat karena limbah yang dihasilkan & 0,06 & 2,17 & 0,13 \\
Pandemi yang mempengaruhi kegiatan & 0,08 & 2,17 & 0,17 \\
Semakin berkembangnya industri pengolahan produk & 0,08 & 2,33 & 0,18 \\
peternakan & & & \\
Produktivitas yang belum stabil & 0,08 & 2,17 & 0,17 \\
\hline Jumlah & 0,43 & 13,50 & 0,98 \\
\hline Total Skor Tertimbang & 1,00 & 34,50 & 2,98 \\
\hline Sumber : Data prim
\end{tabular}

Sumber : Data primer diolah (2021)

Faktor yang menjadi peluang utama subsektor peternakan Kota Yogyakarta adalah pertumbuhan ekonomi dengan skor sebesar 0,34. Sedangkan faktor yang menjadi ancaman utama subsektor peternakan Kota Yogyakarta adalah adanya kasus pencurian ternak dengan skor sebesar 0,20. Total skor tertimbang yang didapatkan dari analisis menggunakan Matriks EFE menunjukan nilai sebesar 2,98, Nilai tersebut memiliki makna bahwa subsektor peternakan masih mampu menarik keuntungan dari peluang eksternal dan mampu menghindari ancaman yang ada.

\section{Matriks IE (Internal External)}

Berdasarkan hasil analisis, nilai total skor tertimbang untuk matriks IFE sebesar 2,66 dan nilai total skor tertimbang untuk matriks EFE sebesar 2,98. 
Puspitasari et.al., Peran dan Strategi Pengembangan Subsektor Peternakan Untuk..

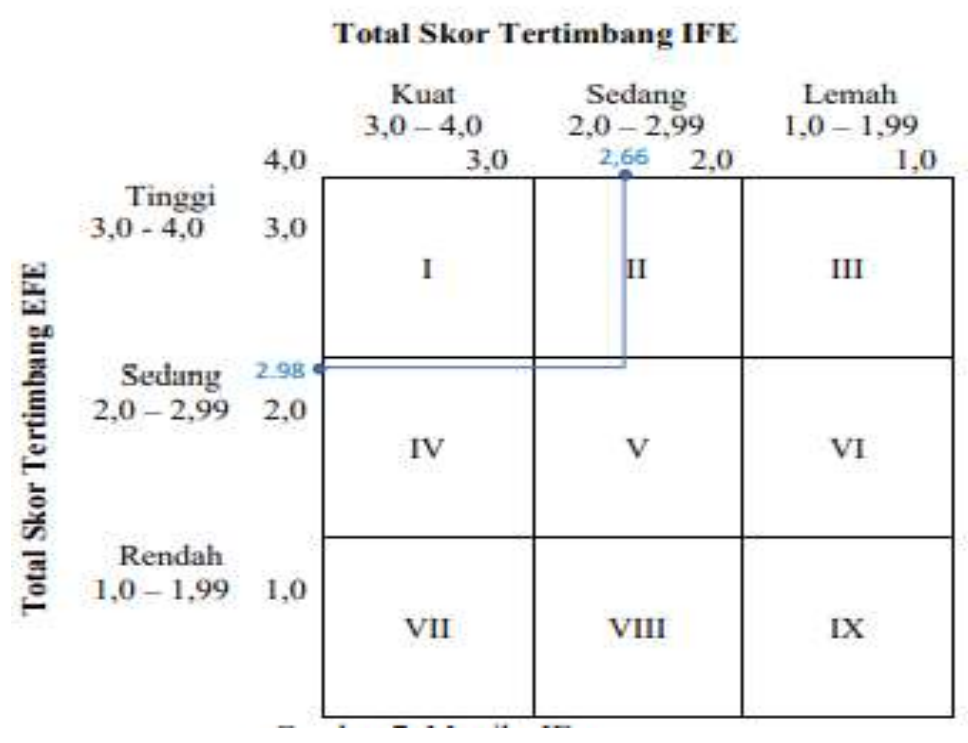

Gambar 1. Hasil Matriks IE

Sumber : Data Primer (2021)

Hasil dari pemetaan nilai total matriks EFI dan matriks EFE menggunakan matriks IE berada di sel 5, posisi tersebut menunjukkan bahwa kedudukan faktor internal sedang dan faktor eksternal sedang maka dengan kedudukan tersebut dapat diterapkan jenis strategi menjaga dan mempertahankan (hold and maintain) yaitu dengan penetrasi pasar dan pengembangan produk. Strategi penetrasi pasar merupakan strategi yang berusaha untuk meningkatkan market share suatu produk atau jasa melalui usaha-usaha pemasaran yang lebih besar. Strategi pengembangan produk merupakan strategi yang berusaha untuk meningkatkan atau memodifikasi produk atau jasa yang ada sehingga dapat meningkatkan penjualan (Yudha, 2016).

\section{Analisis SWOT}

Analisis SWOT bertujuan mengidentifikasi berbagai faktor yang ada untuk merumuskan strategi yang akan ditempuh. Analisis didasarkan pada logika yang dapat memaksimalkan kekuatan dan peluang serta secara bersamaan mampu meminimalkan kelemahan dan ancaman Irawati (2015). Hasil analisis menggunakan Matriks SWOT menghasilkan empat macam kombinasi alternatif strategi antara lain strategi SO, strategi WO, strategi ST, dan strategi WT. 
Tabel 4. Hasil analisis SWOT

\begin{tabular}{|c|c|c|}
\hline & $\begin{array}{l}\text { Kekuatan (Strenghts) } \\
\text { 1. Ketersediaan sumber } \\
\text { daya } \\
\text { 2. } \begin{array}{l}\text { Basis ekonomi } \\
\text { peternakan }\end{array} \\
\text { 3. Koordinasi antar } \\
\text { seksi/bidang/lembaga } \\
\text { 4. Kebijakan } \\
\text { pemerintah } \\
\text { 5. Terdapat kelompok } \\
\text { ternak } \\
\text { 6. Pengelolaan sarana } \\
\text { yang ada }\end{array}$ & $\begin{array}{l}\text { Kelemahan (Weaknesss) } \\
\text { 1. Kurang meratanya } \\
\text { persebaran peternakan } \\
\text { 2. Pengetahuan yang } \\
\text { dimiliki peternak rendah } \\
\text { 3. Peternak belum satu visi } \\
\text { dalam mengembangkan } \\
\text { peternakannya } \\
\text { 4. Minimnya kegiatan dari } \\
\text { pemerintah di bidang } \\
\text { peternakan } \\
\text { 5. Keterbatasan modal } \\
\text { usaha } \\
\text { 6. Belum semua peternak } \\
\text { melakukan pengolahan } \\
\text { produk }\end{array}$ \\
\hline $\begin{array}{l}\text { Peluang (Opportunities) } \\
\text { 1. Kota Yogyakarta sebagai } \\
\text { jalur distribusi pangan } \\
\text { 2. Ketertarikan masyarakat } \\
\text { terhadap peternakan yang } \\
\text { bersifat rekreasi dan hobi } \\
\text { 3. Pertumbuhan ekonomi } \\
\text { 4. Kebutuhan pangan hewan } \\
\text { meningkat } \\
\text { 5. Pengolahan limbah ternak } \\
\text { 6. Meningkatnya permintaan } \\
\text { komoditas ternak di kondisi } \\
\text { tertentu }\end{array}$ & $\begin{array}{ll}\text { Strategi SO: } \\
\text { 1. } & \text { Perbaikan kualitas } \\
\text { ternak untuk } \\
\text { menghasilkan } \\
\text { prpduk ternak yang } \\
\text { aman (S1, S3, S5, } \\
\text { S6, O4, O6) } \\
\text { 2. } \\
\text { Memaksimalkan } \\
\text { pengolahan limbah } \\
\text { ternak (S3, S5,S6, } \\
\text { O4,O5,O6) }\end{array}$ & $\begin{array}{l}\text { Strategi WO: } \\
\text { 1. Meningkatkan } \\
\text { ketrampilan dan } \\
\text { pengetahuan } \\
\text { sumberdaya manusia } \\
\text { (W2, W3, W4, O2, O4, } \\
\text { O6) } \\
\text { 2. Penguatan modal bagi } \\
\text { peternak (W1, W5, W6, } \\
\text { O4, O6) }\end{array}$ \\
\hline $\begin{array}{l}\text { Ancaman (Treaths) } \\
\text { 1. Adanya penyakit ternak } \\
\text { 2. Adanya kasus pencurian } \\
\text { ternak } \\
\text { 3. Protes masyarakat karena } \\
\text { limbah yang dihasilkan } \\
\text { 4. Pandemi yang } \\
\text { mempengaruhi kegiatan } \\
\text { 5. Semakin berkembangnya } \\
\text { industry pengolahan } \\
\text { produk peternakan } \\
\text { 6. Produktivitas yang belum } \\
\text { stabil }\end{array}$ & $\begin{array}{l}\text { Strategi ST: } \\
\text { Peningkatan koordinasi } \\
\text { dan pelayanan terkait } \\
\text { kesehatan ternak (S3, S5, } \\
\text { S6, T1, T6) }\end{array}$ & $\begin{array}{l}\text { Strategi WT: } \\
\text { Sosialisasi dan } \\
\text { pendampingan pembuatan } \\
\text { produk olahan ternak } \\
\text { (bimbingan teknis untuk } \\
\text { agroindustry peternakan) } \\
\text { (W3, W4, W5, W6, T5) }\end{array}$ \\
\hline
\end{tabular}

Sumber : Data primer diolah, 2021

Berdasarkan Tabel 4. Hasil SWOT, setiap kombinasi strategi memiliki nilai rata-rata strategi. Strategi yang memiliki nilai rata-rata paling tinggi dapat dipilih 
Puspitasari et.al., Peran dan Strategi Pengembangan Subsektor Peternakan Untuk..

sebagai startegi yang dapat diimplementasikan. Nilai rata-rata dari setiap kombinasi strategi SWOT didapatkan dari perhitungan di tabel 5

Tabel 5. Hasil perhitungan rata-rata strategi SO, WO, ST, dan WT

\begin{tabular}{lll}
\hline & Kekuatan & Kelemahan \\
\hline Peluang & SO $=($ skor rata-rata kekuatan + & WO $=($ skor rata-rata kelemahan + \\
& skor rata-rata peluang $): 2$ & skor rata-rata peluang $): 2$ \\
& SO $=(0,35+0,33): 2=0,34$ & WO $=(0,10+0,33): 2=0,215$ \\
\hline Ancaman & ST $=($ skor rata-rata kekuatan + & WT $=($ skor rata-rata kelemahan + \\
& skor rata-rata ancaman $): 2$ & skor rata-rata ancaman $): 2$ \\
& ST $=(0,34+0,16): 2=0,25$ & WT $=(0,10+0,16): 2=0,13$ \\
\hline
\end{tabular}

Sumber : Data primer diolah (2021)

\section{Analisis QSPM (Quantitive Strategic Planning Matrix)}

Penentuan prioritas tersebut menggunakan nilai daya tarik sehingga nantinya strategi dengan nilai total TAS yaitu jumlah keseluruhan dari daya tarik total yang nilainya paling tinggi akan menunjukkan strategi tersebut merupakan strategi paling menarik. Hasil analisis QSPM dapat diketahui pada tabel 6.

Tabel 6. Hasil Analisis QSPM

\begin{tabular}{|c|c|c|c|c|c|c|}
\hline \multirow[t]{3}{*}{ No. } & \multirow{3}{*}{$\begin{array}{l}\text { Faktor-Faktor } \\
\text { Utama }\end{array}$} & \multirow[t]{3}{*}{ Bobot } & \multicolumn{4}{|c|}{ Alternatif Strategi } \\
\hline & & & \multicolumn{2}{|c|}{$\begin{array}{l}\text { Penetrasi } \\
\text { Pasar }\end{array}$} & \multicolumn{2}{|c|}{$\begin{array}{l}\text { Pengembangan } \\
\text { Produk }\end{array}$} \\
\hline & & & $\mathbf{A S}$ & TAS & $\mathbf{A S}$ & TAS \\
\hline \multicolumn{7}{|c|}{ Faktor Internal Kekuatan } \\
\hline 1. & Ketersediaan sumber daya alam & 0,10 & 4 & 0,40 & 4 & 0,40 \\
\hline 2. & Basis ekonomi peternakan & 0,10 & 4 & 0,40 & 4 & 0,40 \\
\hline 3. & $\begin{array}{l}\text { Koordinasi } \\
\text { seksi/bidang/lembaga }\end{array}$ & 0,11 & 4 & 0,46 & 4 & 0,46 \\
\hline 4. & Kebijakan dari pemerintah & 0,10 & 4 & 0,40 & 3 & 0,30 \\
\hline 5. & $\begin{array}{l}\text { Adanya pertemuan rutin } \\
\text { kelompok ternak }\end{array}$ & 0,11 & 3 & 0,33 & 4 & 0,44 \\
\hline 6. & Pengelolaan sarana yang ada & 0,11 & 3 & 0,34 & 3 & 0,34 \\
\hline \multicolumn{7}{|c|}{ Faktor Internal Kelemahan } \\
\hline 1. & $\begin{array}{l}\text { Belum meratanya persebaran } \\
\text { komoditas peternakan }\end{array}$ & 0,05 & 2 & 0,10 & 2 & 0,10 \\
\hline 2. & $\begin{array}{l}\text { Pengetahuan budidaya peternak } \\
\text { rendah }\end{array}$ & 0,06 & 2 & 0,12 & 2 & 0,12 \\
\hline 3. & $\begin{array}{l}\text { Peternak belum satu visi dalam } \\
\text { mengembangkan peternak }\end{array}$ & 0,06 & 2 & 0,12 & 2 & 0,12 \\
\hline 4. & $\begin{array}{l}\text { Masih minimnya kegiatan dari } \\
\text { pemerintah dibidang peternakan }\end{array}$ & 0,05 & 3 & 0,16 & 3 & 0,16 \\
\hline 5. & $\begin{array}{l}\text { Modal usaha peternak yang } \\
\text { terbatas }\end{array}$ & 0,07 & 2 & 0,14 & 2 & 0,14 \\
\hline
\end{tabular}




\begin{tabular}{|c|c|c|c|c|c|c|}
\hline 6. & $\begin{array}{l}\text { Belum semua } \quad \text { peternak } \\
\text { melakukan pengolahan produk }\end{array}$ & 0,07 & 2 & 0,14 & 4 & 0,28 \\
\hline \multicolumn{7}{|c|}{ Faktor Eksternal Peluang } \\
\hline 1. & $\begin{array}{l}\text { Lokasi Kota Yogyakarta sebagai } \\
\text { jalur distribusi pangan }\end{array}$ & 0,10 & 4 & 0,41 & 4 & 0,41 \\
\hline 2. & $\begin{array}{l}\text { Minat masyarakat terhadap } \\
\text { peternakan yang bersifat rekreatif } \\
\text { dan hobies }\end{array}$ & 0,09 & 4 & 0,35 & 4 & 0,35 \\
\hline 3. & Pertumbuhan ekonomi & 0,10 & 4 & 0,39 & 4 & 0,39 \\
\hline 4. & $\begin{array}{l}\text { Kebutuhan pangan hewani yang } \\
\text { meningkat }\end{array}$ & 0,09 & 4 & 0,37 & 4 & 0,37 \\
\hline 5. & $\begin{array}{l}\text { Pengolahan kotoran hewan oleh } \\
\text { masyarakat }\end{array}$ & 0,09 & 4 & 0,37 & 4 & 0,37 \\
\hline 6. & $\begin{array}{l}\text { Menigkatnya permintaan hewan } \\
\text { ternak di kondisi tertentu }\end{array}$ & 0,10 & 4 & 0,39 & 4 & 0,39 \\
\hline \multicolumn{7}{|c|}{ Faktor Eksternal Ancaman } \\
\hline 1. & Adanya penyakit ternak & 0,06 & 2 & 0,12 & 4 & 0,23 \\
\hline 2. & Adanya kasus pencurian ternak & 0,09 & 1 & 0,09 & 1 & 0,09 \\
\hline 3. & $\begin{array}{l}\text { Protes masyarakat terhadap } \\
\text { limbah yang dihasilkan }\end{array}$ & 0,06 & 4 & 0,23 & 4 & 0,23 \\
\hline 4. & Terbatasnya kegiatan kelompok & 0,08 & 4 & 0,31 & 4 & 0,31 \\
\hline 5. & $\begin{array}{l}\text { Semakin berkembangnya industri } \\
\text { pengolahan produk peternakan }\end{array}$ & 0,08 & 3 & 0,23 & 4 & 0,31 \\
\hline 6. & Produktivitas yang belum stabil & 0,08 & 2 & 0,15 & 2 & 0,15 \\
\hline Total & & & & 6,50 & & 6,84 \\
\hline
\end{tabular}

Sumber : Data primer diolah (2021)

Berdasarkan Tabel 6. Hasil Analisis QSPM, nilai total TAS strategi pengembangan produk sebesar 6,84 sedangkan nilai TAS strategi penetrasi pasar sebesar 6,50 sehingga strategi yang dapat diimplementasikan adalah strategi pengembangan produk. Analisis sebelumnya yang menggunakan matriks SWOT, didapatkan jenis kombinasi strategi yang dapat diimplementasikan yaitu strategi SO. Strategi SO terdiri dari dua strategi yaitu perbaikan kualitas ternak untuk menghasilkan produk ternak yang aman dan memaksimalkan pengolahan produk limbah ternak. Guna mendapatkan kualitas ternak yang baik diperlukan adanya perhatian di bagian produksi dan pemasaran. Hal tersebut menurut Eviyati (2005), budidaya harus dapat berjalan beriringan dengan pemasaran sehingga bisa diperoleh hasil produksi berupa ternak maupun produk turunan dan olahan peternakan yang berkualitas baik. Apabila target budidaya terpenuhi maka pemasaran pun akan melakukan fungsinya dengan baik. Menurut Talib (2007) dukungan di bagian budidaya dapat didukung dengan berbagai kegiatan antara lain 
Puspitasari et.al., Peran dan Strategi Pengembangan Subsektor Peternakan Untuk..

pemuliaan ternak, untuk pengembangan breed baru, pengembangan teknologi pengendalian penyakit secara terpadu, pengembangan teknologi produksi pakan ternak, serta pengembangan teknologi produksi pakan ternak.

Pengolahan limbah perlu dimaksimalkan hal ini dikarenakan menurut Adityawarman (2015) limbah dapat dimanfaatkan sebagai biogas. Pemanfaatan biogas digunakan sebagai sumber energi dalam kebutuhan rumah tangga. Sisa kotoran hasil pembuatan biogas masih dapat diolah menjadi pupuk padat dan pupuk cair. Pupuk tersebut dapat digunakan sebagai pupuk organic yang dapat menggantikan peran pupuk anorganik. Pengolahan limbah ternak dapat menjadi solusi untuk menghasilkan pangan yang lemih aman dikonsumsi dan mengurangi efek pencemaran lingkungan dari ternak sekaligus sebagai sumber energi alternatif. Selain itu menurut Sukamta (2017), hasil analisis nilai tambah dan pendapatan usaha menunjukkan bahwa pengolahan limbah untuk pembuatan pupuk organic memberikan keuntungan yang cukup signifikan. Sehingga dapat disimpulkan bahwa strategi pengembangan untuk subsektor peternakan di Kota Yogyakarta adalah strategi pengembangan produk.

\section{SIMPULAN}

Subsektor peternakan merupakan subsektor basis dengan nilai LQ rataratanya selama sepuluh tahun yaitu tahun 2010-2019 sebesar 3,317, sehingga dengan nilai tersebut menunjukkan subsektor peternakan memiliki peran besar dalam perekonomian Kota Yogyakarta. Subsektor peternakan dapat dikembangkan untuk menunjang perekonomian Kota Yogyakarta melalui upaya strategi. Strategi pengembangan produk dapat dicapai dengan cara perbaikan kualitas ternak sehingga menghasilkan produk olahan ternak yang aman dan memaksimalkan pengolahan produk limbah ternak.

Pemerintah Kota Yogyakarta harus meningkatkan kegiatan-kegiatan pengembangan subsektor peternakan, pengembangan subsektor peternakan dapat ditempuh dengan berbagai cara yaitu dengan bimbingan teknis mengenai kegiatan agroindustri peternakan, penguatan modal sehingga dapat dapat meningkatkan pendapatan. Pemerintah Kota Yogyakarta juga dapat membuat kebijakan untuk 
Jurnal Dinamika Sosial Ekonomi, 22 (2) : 179-193

peningkatan pembinaan budidaya dan produk kehewanan. Kebijakan berupa kegiatan perbaikan kualitas ternak, memaksimalkan pengolahan produk-produk hasil peternakan, memaksimalkan peran penyuluh terhadap anggota kelompok tani, mempermudah ketersediaan modal usaha lebih aktif untuk memberikan dukungan kepada pelakupelaku usaha di bidang peternakan.

\section{DAFTAR PUSTAKA}

Adityawarman, A. C. (2015). Pengolahan Limbah Ternak Sapi Secara Sederhana di Desa Pattalassang Kabupaten Sinjai Sulawesi Selatan. Jurnal Ilmu Produksi dan Teknologi Hasil Peternakan, 3 (3),171-177. doi: 10.29244/jipthp.3.3.171-177.

Badan Pusat Statistik (2015). Produk Domestik Regional Bruto Kota Yogyakarta Menurut Lapangan Usaha (Gross Regional Domestic Product of Yogyakarta City by Industrial Origin) 2010-2014. Katalog BPS Kota Yogyakarta 930208.3471

Badan Pusat Statistik (2020). Produk Domestik Regional Bruto Kota Yogyakarta Menurut lapangan Usaha (Gross Regional Domestic Product of Yogyakarta Municipality by Industri) 2015-2019. Katalog BPS Kota Yogyakarta 9302021.3471

David, F.R. (2016). Manajemen Strategis Konsep Edisi Kedua Belas Buku Satu. Jakarta : Salemba Empat. 600 hlm.

Eviyati, R. (2005) 'TINJAUAN AGRIBISNIS PETERNAKAN Oleh':, Jurnal AGRIJATI, 1(1), 30-37.

Irawati, D. A., Hubeis, M. and Muksin, M. (2015) 'Strategi Pengembangan Koperasi Peternak Galur Murni Di Kabupaten Jember', Jurnal Aplikasi Bisnis dan Manajemen, 3(1), 123-130. doi: 10.17358/jabm.3.1.123.

Nazir, M. (2014). Metode Penelitian. Cetakan 9. Bogor: Penerbit Ghalia Indonesia

Puradireja, R. H. and Firman, A. (2021) 'Peran Subsektor Peternakan Terhadap Sektor Pertanian pada Perekonomian Wilayah Provinsi Lampung', 7(2), 1161-1173.

Rangkuti, F. (2018). Analisis SWOT: Teknik Membedah Kasus Bisnis Cara Perhitungan Bobot, rating, dan OCAI (Cetakan keduapuluh empat). Jakarta: PT.Gramedia Pustaka Utama 
Puspitasari et.al., Peran dan Strategi Pengembangan Subsektor Peternakan Untuk..

Rustiadi, E. (2011). Perencanaan dan Pengembangan Wilayah. Jakarta : Yayasan Pustaka Obor Indonesia

Setyowati, N. (2017) 'Strategi Pengembangan Subsektor Peternakan dalam Rangka Memperkuat Sektor Pertanian di Kabupaten Boyolali', Sains Peternakan, 9(1), 32-40. doi: 10.20961/sainspet.v9i1.4760.

Sugiyono. (2019). Metode Penelitian Kuantitatif, Kualitatif, dan R\&D. Bandung : Alfabeta. $44 \mathrm{hlm}$

Sukamta, S., Abdus Shomad, M. and Wisnujati, A. (2017) 'Pengelolaan Limbah Ternak Sapi Menjadi Pupuk Organik Komersial di Dusun Kalipucang, Bangunjiwo, Bantul, Yogyakarta', BERDIKARI: Jurnal Inovasi dan Penerapan Ipteks, 5(1), 1-10. doi: 10.18196/bdr.5113.

Talib, C., Inounu, I. and Bamualim, A. (2007) 'Restrukturisasi Peternakan di Indonesia', Analisis Kebijakan Pertanian, 5(1), 1-14.

Yudha A.T, K. (2016) Analisis Strategi Pada Usaha Kecil Menengah (UKM) Sepatu Ducery's UD.Sumber Rejeki Jombang', Laboratorium Penelitian dan Pengembangan FARMAKA TROPIS Fakultas Farmasi Universitas Mualawarman, Samarinda, Kalimantan Timur, (April), 5-24.

Yulia, Y., Baga, L. M. and Tinaprilla, N. (2015) 'Peran dan Strategi Pengembangan Subsektor Peternakan dalam Pembangunan Kabupaten Agam Sumatera Barat', Jurnal Agribisnis Indonesia, 3(2), 159-176. doi: 10.29244/jai.2015.3.2.159-176. 